\title{
Changing aspirations: the future of transport and health
}

\section{Sustainability and climate change}

I write this as the urgent need to prevent global climate change is being brought to everyone's attention through United Nations debates, Climate Strikes and Extinction Rebellion protests. Minovi has written about the need for a 'plastic straw' moment for sustainable and equitable mobility (http://blogs.worldbank.org/transport/advocating-changewhen-will-transport-have-its-plastic-straw-moment\#comment-129826). Equity, of course, needs to apply both between and within countries. The Sustainable Development Goals (https://www.un.org/sustainabledevelopment/sustainable-development-goals/) apply to HICs as well as to low and middle income countries (LMICs). These are important not only to improve human health and reduce inequalities [disparities] by age, gender, ethnicity, religion, country and socio-economic circumstances, but also for planetary health. I am therefore pleased to bring to your attention the call for manuscripts for a special issue of this journal on Health equity, social inclusion and mobility (https://www.journals.elsevier.com/journal-oftransport-and-health/call-for-papers/health-equity-social-inclusion-and-mobility). The submission portal will open in 2020, through EMAN (see below).

The World Bank has an important 'Sustainable mobility for all' project (http://blogs.worldbank.org/transport/sustainable-mobility-all-changing-mindset-changingpolicies). The phrase 'sustainable transport policies' can also be a source of confusion between different disciplines, as it is used by some to refer to the financial or economic sustainability of an intervention or capital project. In this editorial, I am referring primarily to environmental sustainability. Giles-Corti and colleagues have called on the health sector, including politicians with responsibility for health, to "lead in advocating for integrated multisector city planning that prioritises health, sustainability, and liveability outcomes". They listed eight key factors related to city planning to improve the population's health through interventions to affect transport. Some relate directly to transport: increasing parking costs and reducing parking spaces; designing pedestrian- and cycle-friendly infrastructure; reducing the distances to access public transport; and increasing the safety, affordability and convenience of public transport. Others affect which travel modes are feasible: destination accessibility; employment being distributed equitably across cities; optimising residential density; and creating safe, attractive neighbourhoods to encourage active travel (Giles-Corti et al., 2016). While they highlighted the need for this in LMICs, it is also pertinent for many HICs.

Although we are encouraging submissions on interventions to improve health through enhancing the positive and reducing the negative effects of transport, manuscripts submitted to this journal tend to focus on the many adverse impacts on health of motor vehicle transport, including: greenhouse gas emissions; noise and air pollution; facilitating sedentary travel; injuries; community severance; stress; and loss of green and public spaces to private motor vehicles. It is thus of concern that the number of motor vehicles globally was projected in 2008 to increase by 2.3 billion from 2005 to 2050, with four-fifth of the increase in LMICs (Chamon et al., 2008). Transport developments respond in part to changes in land use and urban form (Stevenson et al., 2016). As de Sá and colleagues comment, land use and urban form in most cities is not random or natural, and although it can be constrained by physical geographies, it is affected by financial and commercial interests: developers lobbying 
governments about plans, regulations and guidelines, and official plans. Financial stakeholders impact city life, regardless of the impacts on liveability, quality of life, wellbeing, or health (de Sá et al., 2019). Various types of city living are also packaged, advertised and sold as urban identities symbolically represented by residential location, school catchment, mode(s) of transport and even the materials used in housing construction. Various permutations and combinations of these become aspirational for some, as a goal, once attained, signalling some measure of success.

Advertising helps to produce and frame aspirations; how we view our environment; and social norms (Chapman and Lupton, 1994). Globally, advertisements for cars portray an artificiality that bears little, if any, relation to the reality of driving. Car advertisements equate automobility with 'freedom' and typically a gendered, hyper-masculine, ableist version of power over nature. Cars are often shown traveling along empty winding rural roads with stunning views or located within equally vacant urban roads, selling a message of urban chic, with the perfect mix of intra-vehicular social contact and tag lines such as 'Own the road'. In both variants, there are no other vehicles - and no pedestrians, nor cyclists. The congestion seen in high income countries (HICs) and increasingly in less affluent countries is absent; the low income countries that still have scant traffic do not have the wide, wellmaintained and surfaced roads that are pictured. But we need to remember the political and commercial nature of urban planning decisions (de Sá et al., 2019). Richard Feynman, cited by Rennie (Rennie, 2010), described scientific research as the opposite of advertising: "scientific integrity ....... The idea is to try to give all of the information to help others to judge the value of your contribution; not just the information that leads to judgment in one particular direction or another .... The easiest way to explain this is to contrast it with advertising." (Feynman and Leighton, 1985, p 338).

How do we change aspirations? A senior policy advisor recently said to me that we know what the problems are regarding the effects of health-damaging exposures (such as air pollution) on health. What we need is evidence on what works to reduce risk. This journal can help collate this evidence by hosting a special issue on Transport-related interventions to improve health. If you might be interested in editing this virtual special issue, please contact me via the journal website ${ }^{1}$.

A report from the International Transport Forum (ITF) estimated that replacing private cars with shared vehicles would reduce emissions of greenhouse gases; reduce congestion (the report claims it would 'end' congestion); and increase the availability of public space currently used for parking for other uses (International Transport Forum, 2017).

A joint Ministerial Declaration in 2019 stated that "Transport connectivity is a major contributor to economic development and social inclusion" (International Transport Forum, 2019). What could that money achieve if spent on public transport, active travel infrastructure, and support for liveable communities, as well as achieving other Sustainable Development Goals? It would cost $\$ 100 \mathrm{bn}$ to upgrade the world's slums (Marmot, 2008); by 2009 , more than $\$ 5$ trillion had been spent bailing out financial institutions in high income countries (Marmot and Bell, 2009).

\footnotetext{
${ }^{1}$ https://www.journals.elsevier.com/journal-of-transport-and-health/editorial-board/jennifer-s-mindellbsc-mb-bs-phd-ffph-frcp - scroll to the bottom of the webpage
} 


\section{Air and noise pollution}

\subsection{Ambient air pollution}

Air pollution has recently become a political 'hot potato' in many countries and cities. In most countries, motor vehicles are a major contributor both to criterion pollutants and to carbon emissions (Morales Sarriera and Sehmi, 2019; RCP and RCPCH, 2016). In a cohort of elderly Chinese residents of Hong Kong, a one million increase in annual vehicle kilometres travelled was associated with an increase of $0.81 \%$ in cardiovascular mortality and $0.45 \%$ for all non-traumatic causes of death (Thach et al., 2019). The Global Fuel Economy Initiative is set to invest $\$ 400$ trillion in vehicles and fuel by 2050 , to double fuel efficiency and reduce greenhouse gas emissions (https://www.fiafoundation.org/blog/2014/may/gfei-briefs-unsecretary-general-at-global-climate-conference). However, the same report states that the vehicle fleet is set to triple in that time, thus fuel consumption and all the other adverse consequences of motor vehicles will still increase. In the meantime, national governmental policies are incentivising more private car use. Begg and Haigh (2018) reported that in response to the freeze in UK fuel duty since 2011, public transport usage had fallen and motor traffic had grown by $4 \%$ by 2018 , with adverse effects on pollution and congestion. This produced an additional 4.5 million tonnes of $\mathrm{CO}_{2} ; 12,000$ tonnes of $\mathrm{NO}_{x}$; and 816 tonnes of $\mathrm{PM}_{10}$ particles. It also cost the government $£ 7$ billion in lost tax revenue (Begg and Haigh, 2018). A recent report by the International Transport Forum (TF) commented that the mean mass of passenger cars in the European Union has increased over the past 40 years by about $40 \%$, resulting in higher fuel use and $\mathrm{CO}_{2}$ emissions. The ITF reports that reducing cars' mass from $1,400 \mathrm{~kg}$ to $1,000 \mathrm{~kg}$ (and vans from $1800 \mathrm{~kg}$ to $1100 \mathrm{~kg}$ ) by 2050 could reduce $\mathrm{CO}_{2}$ emissions by $40 \%$, compared with 1990 levels. Lighter cars would also save more money from lower fuel use than the additional costs of producing lighter vehicles (https://www.itf-oecd.org/less-heavy-vehicles-cut-co2-emissions).

Regional and municipal policies can be very effective. Public concern about exposure to air pollution may enable politicians to take bolder steps to implement step changes in transport policy, such as progressing the longstanding but scarcely implemented plan for 'superblocks' (superilla) in Barcelona. This distinguishes grids of roads at roughly $400 \mathrm{~m}$ intervals, designed for through traffic, from street grids within those, designed for citizens to use for a wide variety of purposes (http://ajuntament.barcelona.cat/superilles/ca/superilla/sant-marti ). The Ultralow Emission Zone (ULEZ) in London that came into force in April 2019 charges drivers a daily fee for entering the ULEZ unless they have Euro VI engines for lorries or buses, Euro 6 for diesel cars and vans, or Euro 4 for petrol cars and vans. It has already resulted in a fall of $31 \%$ in $\mathrm{NO}_{2}$ emissions and $29 \%$ in $\mathrm{NO}_{2}$ levels, with no increases in the areas around the zone (Mayor of London, 2019).

Ma and colleagues (2019) show that the spatial and time-related variations in personal exposure to air pollution are underestimated by assessments dependent on fixed monitors. They also showed that the variation in exposure by travel mode is small at low ambient pollution levels but increases at high levels, with lowest exposure for walking compared with car and public transport use (Ma et al., 2019).

\subsection{Air pollution in subway systems}

Concern has been expressed about air pollution exposure of metro [subway] commuters and workers. Different studies have found different results in terms of whether particulates in metros are more or less concentrated than those in ambient air. Although levels of iron, 
chromium and manganese are two orders of magnitude higher in the New York subway than in ambient air (Chillrud et al., 2004), exposure of subway workers was within occupation limits and was not substantially different from office workers (Grass et al., 2010). While most studies attribute these levels to steel dust, Boudia and colleagues found that metro manganese primarily reflected pollution from motor vehicles in ambient air (Boudia et al., 2006). Ventilation fans can reduce particulate levels in metros (Kim et al., 2016). Roy and colleagues examined levels of carcinogens in metro air; although significant, they were within World Health Organization (WHO) limits (Roy et al., 2019). Whether it is appropriate to use air quality guidance prepared for other environments for assessing pollution in metro systems was discussed by Cohen et al. (2013). They found that most of the metros examined were using air pollution regulations designed for ambient air, for a very wide range of pollutants, but others used either much stricter or much higher thresholds. The former may cause unnecessary costs to the metro system, whereas the latter may impose greater health risks for employees and/or passengers.

Why is the metro important and unique? The types of particulates found are different to those in other transport environments. Levels of fine particulates in the London metro are lower than in ambient air but there are higher concentrations of larger particles, two-thirds of which are iron (Seaton, 2005). In Helsinki, particulates in the metro system reflected ambient air, regarding size and concentration. A half hour commute by metro, with a 9 minute average stay at the stations, increased $\mathrm{PM}_{2.5}$ exposure by only $3 \%$ compared with exposure to urban traffic, although exposure to metals increased substantially more (Aarnio et al., 2005).

Occupational exposure might be considered more troubling, given the prolonged exposure, but Seaton and colleagues (2005) showed that occupational exposure in the London metro is an order of magnitude lower than WHO limits. However, workers are generally healthier, and thus less susceptible to the adverse effects of air pollutant exposure, than passengers who may have pre-existing cardiorespiratory disease - although the latter group will be exposed for much shorter periods.

\subsection{Noise}

Noise from transport can reduce children's educational attainment, contributing to longterm social and health inequalities. Noise has adverse effects on health through increasing blood pressure; reducing concentration; and interfering with sleep. Every mode of transport in the Île-de-France resulted in exposure to noise levels above an average LAeq of $70 \mathrm{~dB}$ (Kreuzberger et al., 2019). A large Danish study has found that traffic noise more than doubled the odds of having poor mental health and higher perceived stress levels (Jensen et al., 2018). Mental illness can itself have major impacts on people's ability to travel. The wide range of problems are discussed in a report of some recent qualitative work (Mackett, 2019).

For non-users, the main concern about motorcycle use is often the noise they generate. However, the risks experienced by motorcycle users are generally high road travel injury and fatality rates (Dapilah et al., 2017; González-Sánchez et al., 2018), and musculoskeletal problems (Ospina-Mateus and Quintana Jiménez, 2019). 


\section{Physical activity}

\subsection{Relationship of travel to total PA}

One of the papers in this issue, from a study in the Netherlands and the USA, confirms that active travel is generally additional to, not a replacement for, leisure time physical activity (Panik et al., 2019). A recent study concluded unsurprisingly that assessing different travel modes was better than using driving status to determine sedentary and physical activity (Hajna et al., 2019). This is important, as sedentary behaviour is associated with subsequent development of diabetes and cardiovascular disease (CVD), although the latter association is attenuated when adjusted for physical activity (Bailey et al., 2019). A recent systematic review has shown that building new public transport [transit] increases walking and other light to moderate intensity physical activity by about 30 minutes per week (Xiao et al., 2019).

Such studies are not possible, however, without adequate assessment of active travel, which has generally required bespoke data. The study by Hajna and colleagues was unusual in being very large (>90,000 participants) and including accelerometry, albeit in a nonrepresentative sample. Three articles in this issue address this problem. The first finds that walking to public transport can be estimated using open source data (Grisé et al., 2019). Although this underestimates distances walked by $3 \%$, on average, Grisé and colleagues provide adjustments for transport practitioners wishing to use open source data to estimate walking to different types of public transport in their area. The second shows that measuring cycling in a research study needs to balance bias against accuracy. Initial surveys provide larger, more representative samples but tend to reflect 'usual' cycling, while repeated measurements produce more accurate estimates of actual cycling (Branion-Calles et al., 2019). Finally, Garber and colleagues have reported an excellent pilot study of using smartphone apps to measure cycling and how this affects selection bias and representativeness (Garber et al., 2019).

\subsection{Walking}

Pedestrians are often the forgotten travellers, with their comfort and time ignored. The many people on foot waiting for signalised crossings to allow them to proceed - while occasional drivers speed past - would be surprised to learn that in 1988, the European Parliament adopted the European Charter of Pedestrians' Rights. This stated (8, p. 16): 'the pedestrian has the right to live in a healthy environment and to freely enjoy the amenities offered by public areas under conditions that adequately safeguard his physical and psychological well being' (Sarkar, 2003). Last month I was run over, while walking on the pavement, by someone on an e-scooter who came up behind me (in a country where they are illegal on the pavement but there is little enforcement of legislation).

It is strange that although almost everyone is a pedestrian some of the time (in most countries, at least), walking is so often invisible to those making or implementing travel policy. Andrews et al made a similar point last year about disabled people and cycling: although a potentially important travel mode to increase independence, disabled people are seldom seen in cycling literature (Andrews et al., 2018). Clayton et al have also pointed out their invisibility in research (Clayton et al., 2017).

In Helsinki in $2013,77 \%$ of daily trips were by active travel, despite the low population density, winter climate, and high driving rates nationally. Saidla (2018) attributes this success for active travel to a pro-active travel coalition that dominated municipal transportation policy over the longterm but not to health promotion. The coalition were 
primarily concerned to improve liveability. In this issue, Sugiyama and colleagues assess the distances that people generally walk, finding that buffers of $600-1200 \mathrm{~m}$ are appropriate for studies of walking and the local environment (Sugiyama et al., 2019). Land use diversity, street connectivity, residential density and public transport access are features of the built environment associated with walkability in general population studies (Dhanani et al., 2017) and among American adolescents (Tewahade et al., 2019). Schreuer and colleagues show in this issue that these are also relevant to travel opportunities for people with disabilities, with slope as an additional important feature (Schreuer et al., 2019). A study of active travel in Wisconsin, USA found that the number of non-residential destinations within a 10minute walk was associated with more active travel (Grabow et al., 2019). However, land use mix and residential density were also associated with depression in a study in Guangzhou, China (Zhang et al., 2019).

Saidla makes the point that readers of this journal will be well aware of - that health practitioners have many natural allies in other fields and organisations. One successful intervention to increase active travel by children is walking school buses. Four benefits of these identified by parent co-ordinators are not only the reduction in car use and congestion and the opportunity for physical activity and health promotion but also reduced injury risk and promoting a sense of community (Collins and Kearns, 2010). The authors postulate that supervised walking, such as these walking school buses, can challenge some of the social and cultural assumptions that maintain automobile dependence (Collins and Kearns, 2010). In one of the largest studies published in this journal, Uddin and colleagues found that twofifths of 106,605 adolescents in 27 Asia-Pacific countries commuted to school using active modes at least three times per week, but this was negatively associated both with the country's income and with the Gini coefficient (a measure of inequality). Active commuting varied by age in different directions in different countries (Uddin et al., 2019, Editor's Choice). When examining the environmental features associated with walking to school in New Zealand, Ikeda and colleagues found, not surprisingly, that distance was the strongest predictor; greater residential density and street connectivity near schools was associated with active travel to school. It is unsurprising, though regrettable, that socioeconomic position was inversely associated with active travel to school travel (Ikeda et al., 2018), echoing the between-country inverse association with active travel found by Uddin et al (2019).

But walking is not always beneficial. In Ghana, a little over half of schoolchildren aged 6-15 surveyed in a peri-urban area near Accra walked to school but few were accompanied by an adult; the paper in this issue describes some of the many hazards these children face when travelling (Poku-Boansi et al., 2019). In poor communities, especially those living in informal settlements in low income countries, people (mostly women) often have no options if they need to travel to and from work but to walk for perhaps two hours each way. In some cases, no other travel mode exists; in others, there are buses but they are unaffordable. Jones and Lucas describe this as 'coercive walking' (Jones and Lucas, 2012). Bostock has described the same phenomenon among poor single mothers in the UK (Bostock, 2001), while the Guangzhou study found the highest adjusted odds of depression among those who walked for travel for more than $2 \mathrm{~h}$ per day (Zhang et al., 2019). Meanwhile, Mark and Heinrichs (2019) point out that there are many factors in addition to time and money affecting travel options and needs for women living in informal settlements in Latin America, including wayfinding and insecurity. One of the reasons that people do not walk or use public transport is fear of crime, often exacerbated by perceptions of neglected environments. In an innovative 
project, Aroyo Moliner and Clavell involved graffiti artists to decorate public transport, transforming threatening signs of dereliction into public art (Arroyo Moliner and Clavell, 2016).

\subsection{Automated Vehicles}

Are automated vehicles ( $A V s$ ) the panacea that some seem to think? A recent review proposed a range of impacts on health: reducing injuries was paramount, with effects on air quality, physical activity, and stress being less certain (Dean et al., 2019). However, a study in the USA found that the number of pedestrians that could be detected by an AV prior to a fatal collision ranged from below $30 \%$ to above $90 \%$, a range that is not reassuring (Combs et al., 2019). Meanwhile, Booth and colleagues comment in this issue about the impact of AVs on physical activity levels. They found that substantial minorities of Australians surveyed considered themselves likely to use AVs instead of walking or cycling, with almost half expecting to use AVs instead of public transport, thus reducing active travel in a sizeable proportion of the population, particularly those with more favourable attitudes to AVs (Booth et al., 2019).

\section{Motorcycle injuries}

Two articles in this issue report risks in relation to motorcycle use. Motorcycle use is the most dangerous mode of motorised road travel. In the European Union, more than 6500 motorised two wheeler users die each year. The risk of death for motorcyclists is 20 times that of car occupants in High income Countries, and although motorcyclists only account for $1 \%$ of total road traffic, they account for around $18 \%$ of deaths from road collisions. In LMICs, the number of deaths and rates of death are even higher, up to $30 \%$ of all road deaths in some countries (World Health Organization, 2017). Taiwanese adults aged 20-64, who spent at least half an hour daily on motorcycles were almost half as likely to drink alcohol, with no significant association with leisure time physical activity, smoking status or diet, despite the preconceptions that motorcyclists are generally risk-takers (Liao et al., 2019). In the second article, we learn that advance stop lines for motorcycles do not reduce injuries - and may increase them in surrounding areas (Pérez and Santamariña-Rubio, 2019).

\section{Changes to this journal}

This journal starting to receive manuscripts in August 2013; by $28^{\text {th }}$ October 2019, we had published 620 articles: around 62 pa in the first three years and 140 pa in the second three years. This reflects an exponential rise in submissions. They include high quality science relevant to policy and/or practice; manuscripts of a reasonable standard that could be - and often have been - improved by responding to thoughtful feedback from our wonderful panel of reviewers; plus those that are not of sufficient standard or are not within the journal's scope. I can recall only two manuscripts that had nothing to do with transport AND nothing to do with health. One wonders what the authors were thinking when they wasted their own time and mine!

Readers, authors and reviewers will see a few changes in the coming months. This journal will be encouraging the use of Contributor Roles Taxonomy (CRediT), to improve transparency \& integrity around authorship. CRediT aims to capture the several contributions 
that are needed for research and publication of findings by providing 14 defined roles. These are intended to provide greater recognition for each author's work, as well as reducing authorship disputes, and facilitating collaboration. Please note that each author is likely to have contributed in multiple roles, and not all roles may apply to each manuscript. More information is available at https://www.casrai.org/credit.html.

The submission system will also be changing early in 2020 from EVISE to EMAN. Manuscripts that are submitted before the end of 2019 will continue to be processed through EVISE, including revised manuscripts that are resubmitted, but all new submissions in 2020 will be via the new system. Submissions to the two special issues mentioned above will be through EMAN. My strong advice to authors is that you must always read the guide for authors, for the specific journal to which you are submitting a manuscript, even if you have published there before: instructions may change over time. For example, the Journal of Transport and Health has required structured abstracts since mid-2018 but we still have to return a high proportion of manuscripts to provide this, add line numbering, use Harvard format for in-text citations, or other infringements of our basic requirements.

The other major change is that my term of office as Editor-in-chief ceases at the end of December 2019. I am delighted to introduce Associate Professor Charlie Musselwhite, of Swansea University, as my successor. He was guest editor of a special issue on Transport, travel and mobility in later life (https://www.sciencedirect.com/journal/journal-of-transportand-health/vol/2/issue/1) and then became an Associate Editor. I look forward to following the journal's progress over the next few years.

One of my regrets as I hand over the reins is that we failed to generate an evidence-based debate about the efficacy of cycle helmets and the population health impacts of legislation mandating the use of cycle helmets. Those who believe that the evidence is convincing that helmets are beneficial and that legislation is not detrimental (for example by deterring cycling, with the adverse effect of physical activity foregone exceeding any benefits from helmet wearing) were not willing to submit an article to us. Much that has been written has been 'playing the man not the ball' and many of the critiques have been published as blogs, not as peer-reviewed scientific articles. It remains an important issue. A paper describing the magnitude of lives saved by helmet legislation in Australia has recently been published (Olivier et al., 2019). The authors state there is no good evidence of changes in participation in cycling, although others dispute that (Lemon, 2018), and a study of New Zealand adolescents found that one-fifth reported they would cycle to school if helmets were not mandatory (Molina-García et al., 2018). I do not know enough about the presence or absence and the timing of any other interventions, such as cycling infrastructure, or changes to emergency treatment to know whether all 1,332 fewer cycling deaths reported by Olivier and colleagues can be attributed to the cycle helmet legislation. I do wish that someone would persuade the various cycle helmet researchers to work together, in good faith, with pre-specified datasets, timeframes, and analytic approaches so that the critiques of each other's methods could be dealt with in a scientific way a priori, with confidence in the findings and interpretations.

I should like to take this opportunity to thank the Associate and Guest Editors for their work; the Board members and Elsevier staff for their support; the authors for submitting and revising manuscripts; the reviewers for providing an essential service to increase the quality of the papers we have published; and of course the readers of this journal. I could not have 
done it without you. I wish the incoming Editor-in-Chief, Charlie Musselwhite, all the best for the next phase in this journal's history.

Thank you!

\section{References}

Aarnio, P., Yli-Tuomi, T., Kousa, A., Mäkelä, T., Hirsikko, A., Hämeri, K., Räisänen, M., Hillamo, R., Koskentalo, T., Jantunen, M., 2005. The concentrations and composition of and exposure to fine particles (PM2.5) in the Helsinki subway system. Atmos. Environ. 39, 5059-5066. https://doi.org/10.1016/j.atmosenv.2005.05.012

Andrews, N., Clement, I., Aldred, R., 2018. Invisible cyclists? Disabled people and cycle planning - A case study of London. J. Transp. Health 8, 146-156. https://doi.org/10.1016/j.jth.2017.11.145

Arroyo Moliner, L., Clavell, G.G., 2016. The TramArt experience: domesticating graffiti in public transport. J. Place Manag. Dev. 9, 105-115. https://doi.org/10.1108/JPMD-092015-0044

Bailey, D.P., Hewson, D.J., Champion, R.B., Sayegh, S.M., 2019. Sitting Time and Risk of Cardiovascular Disease and Diabetes: A Systematic Review and Meta-Analysis. Am. J. Prev. Med. 57, 408-416. https://doi.org/10.1016/j.amepre.2019.04.015

Begg, D., Haigh, C., 2018. The Unintended Consequences of Freezing Fuel Duty. Transp. Times.

Booth, L., Norman, R., Pettigrew, S., 2019. The potential implications of autonomous vehicles for active transport. J. Transp. Health 15, 100623. https://doi.org/10.1016/j.jth.2019.100623

Bostock, L., 2001. Pathways of disadvantage? Walking as a mode of transport among lowincome mothers. Health Soc. Care Community 9, 11-18. https://doi.org/10.1046/j.1365-2524.2001.00275.x

Boudia, N., Halley, R., Kennedy, G., Lambert, J., Gareau, L., Zayed, J., 2006. Manganese concentrations in the air of the Montreal (Canada) subway in relation to surface automobile traffic density. Sci. Total Environ. 366, 143-147. https://doi.org/10.1016/j.scitotenv.2005.09.094

Branion-Calles, M., Winters, M., Nelson, T., de Nazelle, A., Panis, L.I., Avila-Palencia, I., Anaya-Boig, E., Rojas-Rueda, D., Dons, E., Götschi, T., 2019. Impacts of study design on sample size, participation bias, and outcome measurement: A case study from bicycling research. J. Transp. Health 15, 100651. https://doi.org/10.1016/j.jth.2019.100651

Chamon, M., Mauro, P., Okawa, Y., 2008. Mass car ownership in the emerging market giants. Econ. Policy 23, 243-296. https://doi.org/10.1111/j.1468-0327.2008.00201.x

Chapman, S., Lupton, D., 1994. The fight for public health: principles and practice of media advocacy. BMJ Publ. Group, London.

Chillrud, S.N., Epstein, D., Ross, J.M., Sax, S.N., Pederson, D., Spengler, J.D., Kinney, P.L., 2004. Elevated Airborne Exposures of Teenagers to Manganese, Chromium, and Iron from Steel Dust and New York City's Subway System. Environ. Sci. Technol. 38, 732-737. https://doi.org/10.1021/es034734y

Clayton, W., Parkin, J., Billington, C., 2017. Cycling and disability: A call for further research. J. Transp. Health 6, 452-462. https://doi.org/10.1016/j.jth.2017.01.013

Cohen, J.M., Anderson, R., Melo, P.C., Graham, D.J., Hirsch, R., 2013. Air quality regulation in metropolitan railways: a benchmarking approach. Presented at the 92nd Transportation Research Board Annual Meeting, Washington DC.

Collins, D., Kearns, R.A., 2010. Walking school buses in the Auckland region: A longitudinal assessment. Transp. Policy 17, 1-8. https://doi.org/10.1016/j.tranpol.2009.06.003 
Combs, T.S., Sandt, L.S., Clamann, M.P., McDonald, N.C., 2019. Automated Vehicles and Pedestrian Safety: Exploring the Promise and Limits of Pedestrian Detection. Am. J. Prev. Med. 56, 1-7. https://doi.org/10.1016/j.amepre.2018.06.024

Dapilah, F., Guba, B.Y., Owusu-Sekyere, E., 2017. Motorcyclist characteristics and traffic behaviour in urban Northern Ghana: Implications for road traffic accidents. J. Transp. Health 4, 237-245. https://doi.org/10.1016/j.jth.2016.03.001

de Sá, T.H., Edwards, P., Pereira, R.H.M., Monteiro, C.A., 2019. Right to the city and human mobility transition: The case of São Paulo. Cities 87, 60-67. https://doi.org/10.1016/j.cities.2018.12.024

Dean, J., Wray, A.J., Braun, L., Casello, J.M., McCallum, L., Gower, S., 2019. Holding the keys to health? A scoping study of the population health impacts of automated vehicles. BMC Public Health 19, 1258. https://doi.org/10.1186/s12889-019-7580-9

Dhanani, A., Tarkhanyan, L., Vaughan, L., 2017. Estimating pedestrian demand for active transport evaluation and planning. Transp. Res. Part Policy Pract. 103, 54-69. https://doi.org/10.1016/j.tra.2017.05.020

Feynman, R.P., Leighton, R., 2012. Surely you're joking, Mr Feynman!, Folio Society. ed. The Folio Society, London.

Garber, M.D., Watkins, K.E., Kramer, M.R., 2019. Comparing bicyclists who use smartphone apps to record rides with those who do not: Implications for representativeness and selection bias. J. Transp. Health 15, 100661. https://doi.org/10.1016/j.jth.2019.100661

Giles-Corti, B., Vernez-Moudon, A., Reis, R., Turrell, G., Dannenberg, A.L., Badland, H., Foster, S., Lowe, M., Sallis, J.F., Stevenson, M., Owen, N., 2016. City planning and population health: a global challenge. The Lancet 388, 2912-2924. https://doi.org/10.1016/S0140-6736(16)30066-6

González-Sánchez, G., Maeso-González, E., Olmo-Sánchez, M.I., Gutiérrez-Bedmar, M., Mariscal, A., García-Rodríguez, A., 2018. Road traffic injuries, mobility and gender. Patterns of risk in Southern Europe. J. Transp. Health 8, 35-43. https://doi.org/10.1016/j.jth.2017.11.147

Grabow, M.L., Bernardinello, M., Bersch, A.J., Engelman, C.D., Martinez-Donate, A., Patz, J.A., Peppard, P.E., Malecki, K.M.C., 2019. What moves us: Subjective and objective predictors of active transportation. J. Transp. Health 15, 100625. https://doi.org/10.1016/j.jth.2019.100625

Grass, D.S., Ross, J.M., Family, F., Barbour, J., James Simpson, H., Coulibaly, D., Hernandez, J., Chen, Y., Slavkovich, V., Li, Y., Graziano, J., Santella, R.M., BrandtRauf, P., Chillrud, S.N., 2010. Airborne particulate metals in the New York City subway: A pilot study to assess the potential for health impacts. Environ. Res. 110, 1-11. https://doi.org/10.1016/j.envres.2009.10.006

Grisé, E., Wasfi, R., Ross, N.A., El-Geneidy, A., 2019. Evaluating methods for measuring daily walking to public transport: Balancing accuracy and data availability. J. Transp. Health 15, 100638. https://doi.org/10.1016/j.jth.2019.100638

Hajna, S., White, T., Panter, J., Brage, S., Wijndaele, K., Woodcock, J., Ogilvie, D., Imamura, F., Griffin, S.J., 2019. Driving status, travel modes and accelerometerassessed physical activity in younger, middle-aged and older adults: a prospective study of 90810 UK Biobank participants. Int. J. Epidemiol. 48, 1175-1186. https://doi.org/10.1093/ije/dyz065

Ikeda, E., Stewart, T., Garrett, N., Egli, V., Mandic, S., Hosking, J., Witten, K., Hawley, G., Tautolo, E.S., Rodda, J., Moore, A., Smith, M., 2018. Built environment associates of active school travel in New Zealand children and youth: A systematic meta-analysis using individual participant data. J. Transp. Health 9, 117-131. https://doi.org/10.1016/j.jth.2018.04.007

International Transport Forum, 2019. 2019 Summit Ministerial Declaration on Transport Connectivity for Regional Integration. Leipzig.

International Transport Forum, 2017. Shared Mobility Simulations for Helsinki. Paris. 
Jensen, H.A.R., Rasmussen, B., Ekholm, O., 2018. Neighbour and traffic noise annoyance: a nationwide study of associated mental health and perceived stress. Eur. J. Public Health 28, 1050-1055. https://doi.org/10.1093/eurpub/cky091

Jones, P., Lucas, K., 2012. The social consequences of transport decision-making: clarifying concepts, synthesising knowledge and assessing implications. Soc. Impacts Equity Issues Transp. 21, 4-16. https://doi.org/10.1016/j.jtrangeo.2012.01.012

Kim, G.-S., Son, Y.-S., Lee, J.-H., Kim, I.-W., Kim, J.-C., Oh, J.-T., Kim, H., 2016. Air Pollution Monitoring and Control System for Subway Stations Using Environmental Sensors. J. Sens. 2016, 1-10. https://doi.org/10.1155/2016/1865614

Kreuzberger, N., Chaix, B., Brondeel, R., Méline, J., El Aarbaoui, T., 2019. Transport-related noise exposure in a representative sample of Île-de-France residents: A dataenrichment approach. J. Transp. Health 12, 220-228. https://doi.org/10.1016/j.jth.2019.02.002

Lemon, J., 2018. Changes in participation, demographics and hazard associated with mandatory bicycle helmets in New South Wales, Australia. J. Transp. Health 9, 195202. https://doi.org/10.1016/j.jth.2018.03.011

Liao, Y., Lin, C.-Y., Park, J.-H., 2019. Is motorcycle use associated with unhealthy lifestyles? Findings from Taiwan. J. Transp. Health 15, 100659. https://doi.org/10.1016/j.jth.2019.100659

Ma, J., Tao, Y., Kwan, M.-P., Chai, Y., 2019. Assessing Mobility-Based Real-Time Air Pollution Exposure in Space and Time Using Smart Sensors and GPS Trajectories in Beijing. Ann. Am. Assoc. Geogr. 1-15. https://doi.org/10.1080/24694452.2019.1653752

Mackett, R., 2019. Mental health and travel: Report on a survey. UCL, London.

Mark, L., Heinrichs, D., 2019. More than time and money - Influences on mobility of lowincome women in the Villa 20 in Buenos Aires, Argentina. J. Transp. Health 15, 100652. https://doi.org/10.1016/j.jth.2019.100652

Marmot, M. (Chair), 2008. WHO Commission on Social Determinants of Health: Closing the gap in a generation. World Health Organization, Geneva.

Marmot, M.G., Bell, R., 2009. How will the financial crisis affect health? BMJ 338, b1314b1314. https://doi.org/10.1136/bmj.b1314

Mayor of London, 2019. Central London Ultra Low Emission Zone - Six month report. Greater London Authority, London.

Molina-García, J., Queralt, A., García Bengoechea, E., Moore, A., Mandic, S., 2018. Would New Zealand adolescents cycle to school more if allowed to cycle without a helmet? J. Transp. Health 11, 64-72. https://doi.org/10.1016/j.jth.2018.10.001

Morales Sarriera, J., Sehmi, G.S., 2019. Transport pollution: Some practical solutions for developing countries.

Olivier, J., Boufous, S., Grzebieta, R., 2019. The impact of bicycle helmet legislation on cycling fatalities in Australia. Int. J. Epidemiol. 48, 1197-1203. https://doi.org/10.1093/ije/dyz003

Ospina-Mateus, H., Quintana Jiménez, L.A., 2019. Understanding the impact of physical fatigue and postural comfort experienced during motorcycling: A systematic review. J. Transp. Health 12, 290-318. https://doi.org/10.1016/j.jth.2019.02.003

Panik, R.T., Morris, E.A., Voulgaris, C.T., 2019. Does walking and bicycling more mean exercising less? Evidence from the U.S. and the Netherlands. J. Transp. Health 15, 100590. https://doi.org/10.1016/j.jth.2019.100590

Pérez, K., Santamariña-Rubio, E., 2019. Do advanced stop lines for motorcycles improve road safety? J. Transp. Health 15, 100657. https://doi.org/10.1016/j.jth.2019.100657

Poku-Boansi, M., Amoako, C., Atuah, D.O., 2019. Urban travel patterns and safety among school children around Accra, Ghana. J. Transp. Health 15, 100660. https://doi.org/10.1016/j.jth.2019.100660

$\mathrm{RCP}, \mathrm{RCPCH}$ (Eds.), 2016. Every breath we take: the lifelong impact of air pollution: report of a working party. Royal College of Physicians of London, London. 
Rennie, D., 2010. Integrity in Scientific Publishing: Integrity in Scientific Publishing. Health Serv. Res. 45, 885-896. https://doi.org/10.1111/j.1475-6773.2010.01088.x

Roy, D., Seo, Y.-C., Namgung, H.-G., Kwon, S.-B., 2019. Inhalation cancer risk from PM10 in the metropolitan subway stations in Korea. J. Transp. Health 14, 100580. https://doi.org/10.1016/j.jth.2019.100580

Sarkar, S., 2003. Qualitative evaluation of comfort needs in urban walkways in major activity centers. Transp. Q. 57, 39-59.

Schreuer, N., Plaut, P., Golan, L., Sachs, D., 2019. The relations between walkable neighbourhoods and active participation in daily activities of people with disabilities. J. Transp. Health 15, 100630. https://doi.org/10.1016/j.jth.2019.100630

Seaton, A., 2005. The London Underground: dust and hazards to health. Occup. Environ. Med. 62, 355-362. https://doi.org/10.1136/oem.2004.014332

Stevenson, M., Thompson, J., de Sá, T.H., Ewing, R., Mohan, D., McClure, R., Roberts, I., Tiwari, G., Giles-Corti, B., Sun, X., Wallace, M., Woodcock, J., 2016. Land use, transport, and population health: estimating the health benefits of compact cities. The Lancet 388, 2925-2935. https://doi.org/10.1016/S0140-6736(16)30067-8

Sugiyama, T., Kubota, A., Sugiyama, M., Cole, R., Owen, N., 2019. Distances walked to and from local destinations: Age-related variations and implications for determining buffer sizes. J. Transp. Health 15, 100621. https://doi.org/10.1016/j.jth.2019.100621

Tewahade, S., Li, K., Goldstein, R.B., Haynie, D., Iannotti, R.J., Simons-Morton, B., 2019. Association between the built environment and active transportation among U.S. adolescents. J. Transp. Health 15, 100629. https://doi.org/10.1016/j.jth.2019.100629

Thach, T.-Q., Tsang, H., Lai, P., Lee, R.S., Wong, P.P., 2019. Long-term effects of traffic exposures on mortality in a Chinese cohort. J. Transp. Health 14, 100609. https://doi.org/10.1016/j.jth.2019.100609

Uddin, R., Mandic, S., Khan, A., 2019. Active commuting to and from school among 106,605 adolescents in 27 Asia-Pacific countries. J. Transp. Health 15, 100637. https://doi.org/10.1016/j.jth.2019.100637 [Editors' Choice]

World Health Organization, 2017. Powered two and three wheeler safety: A road safety manual for decisionmakers and practitioners, World Health Organisation. WHO.

Xiao, C., Goryakin, Y., Cecchini, M., 2019. Physical Activity Levels and New Public Transit: A Systematic Review and Meta-analysis. Am. J. Prev. Med. 56, 464-473. https://doi.org/10.1016/j.amepre.2018.10.022

Zhang, T., Chiu, R.L.H., Ho, H.C., 2019. Suburban neighborhood environments and depression: A case study of Guangzhou, China. J. Transp. Health 15, 100624. https://doi.org/10.1016/j.jth.2019.100624 